\title{
VICTIMOLOGÍA EN EL SISTEMA PENAL ACUSATORIO ADVERSARIAL
}

\author{
VICTIMOLOGY IN THE ADVERSARIAL ACCUSATORY CRIMINAL SYSTEM
}

ENMANUEL HERNÁNDEZ ASCENCIO ${ }^{1}$ (D) *; Yazmín Isolda Álvarez-García ${ }^{2}$ (iD; William Baldemar López-Rodríguez ${ }^{3}$ (D); Ragif Huseynov ${ }^{4}$ (D).

1. Escuela Judicial del estado de Tabasco. México. amdcfeha@gmail.com

2. Universidad Juárez Autónoma de Tabasco. México.m.d.yazmin_alvarez@hotmail.com

3. Universidad Juárez Autónoma de Tabasco. México. williambaldemar@hotmail.com

4. Centro Educativo Khazar. ragif1984@gmail.com

*Correspondencia del Autor: Enmanuel Hernández-Ascencio, correo electrónico: amdcfeha@gmail.com.

\section{RESUMEN}

Se describe a la victimología como el estudio del modo en que una persona deviene víctima, de las diversas dimensiones de la victimización (primaria, secundaria y terciaria), y de las estrategias de prevención y reducción de la misma, así como del conjunto de respuestas sociales, jurídicas y asistenciales, tendientes a la reparación y reintegración social de la víctima. Por lo antes citado, este documento aporta apuntes referentes a la importancia complementaria de conocer en amplitud este estudio aplicado a la dupla del delito llamada víctima-victimario en conocer los procesos victimológicos y su alcance para su atención y aplicación en miras de una justicia restaurativa.

Palabras clave: criminología; sistema de justicia; víctima.

Cómo citar:

HERNÁNDEZ ASCENCIO, ENMANUEL; Álvarez-García, Yazmín Isolda; López-Rodríguez, William Baldemar; Huseynov, Ragif. (2020). VICTIMOLOGÍA EN EL SISTEMA PENAL ACUSATORIO ADVERSARIAL. Revista de Investigaciones Universidad del Quindio, 32(2), 33-38. https://doi.org/10.33975/riuq.vol32n2.469 


\begin{abstract}
Victimology is described as the study of the way in which a person becomes a victim, the various dimensions of victimization (primary, secondary and tertiary), and the prevention and reduction strategies, as well as the set of responses social, legal and welfare, aimed at reparation and social reintegration of the victim. Due to the aforementioned, this document provides notes regarding the complementary importance of knowing in depth this study applied to the crime duo called victimperpetrator in knowing the victimological processes and their scope for their attention and application in view of restorative justice.
\end{abstract}

Keywords: criminology; justice system; victim.

\section{INTRODUCCIÓN}

La victimología conforme a su objeto de estudio, señala está constituida en tres planos constitutivos: "1). Primordial bio-psicosocial: en donde el sujeto prevé aquellos factores que lo incitan a víctima, 2) criminológico: relación de bio-psicosocial, problemas de criminalidad desde lo terapéutico victimal, 3) jurídico: vislumbra a la víctima con la ley" (Cuarezma, s.f).

Este esquema parece ser lo suficientemente amplio, admitiendo tanto a la víctima del crimen como otras víctimas, así como diversos campos de aplicación. Este enfoque, según Fattah (2014) satisface una victimología criminológica cuya finalidad es la de desarrollar, a través del estudio de la víctima, un conjunto de reglas generales y de principios comunes, así como otro tipo de conocimientos que puedan contribuir al desarrollo y progreso de las ciencias jurídicas, permitiendo una mejor comprensión del fenómeno criminal.

Ante ese escenario, en las siguientes líneas se ahonda respecto a la importancia complementaria de conocer en amplitud este estudio aplicado a la dupla del delito llamada víctima-victimario en conocer los procesos victimológicos (Márquez, 2011) y su alcance para su atención y aplicación en miras de una justicia restaurativa.

\section{METODOLOGÍA}

Representando la victimología una ciencia sobre la cual se asientan los pilares de un nuevo sistema de justicia, capaz de reordenar y equilibrar el orden social.

En la comprensión compleja del quehacer de la justicia y su interpretación en sentido de protección a la víctima y victimario, este documento se basó en una revisión bibliohemerográfica a partir de la búsqueda, consulta, análisis e interpretación de la doctrina, contemplando lo que la norma señala a disposición para el estado mexicano.

\section{RESULTADOS}

\section{Criterios de la victimología}

La criminología es una ciencia joven en comparación con otras, tan solo centenaria, 
siendo la victimología aún más joven, ya que sus orígenes como tal se remontan a los años treinta del siglo pasado. Hoy existe una Sociedad Mundial de victimología, así como sociedades estatales y regionales, junto con institutos y centros de investigación específicos en Victimología que, además, organizan congresos e imparten cursos y especialidades. Asimismo, existen publicaciones especializadas en la materia en diversos idiomas.

No obstante, no puede afirmarse rotundamente que la victimología sea una disciplina autónoma en relación con la criminología. La criminología se define actualmente como una ciencia interdisciplinar que estudia las relaciones entre la delincuencia, los infractores, las víctimas y el control social, por victimología se entiende la ciencia interdisciplinar que se ocupa del conocimiento relativo a los procesos de victimización y des victimización en un sentido amplio.

El derecho penal como la criminología (Mejías, 2014) han tratado superficialmente a la víctima, pero ninguno de los dos ha sido creado para estudiarla y ayudarla, pues el derecho penal estudia la estructura del delito y la pena; mientras que la criminología estudia las causas del delito, el delincuente y el control social. La victimología nace por una necesidad vital de dignidad humana.

La victimización es el resultado de una conducta antisocial (Vega, 2017) contra un grupo o persona; por el cual se deviene en víctima; es el mecanismo por el cual una persona llega a convertirse en sujeto pasivo del hecho punible, es la apropiación y/o el abuso de una persona por otra. Esta es la llamada victimización criminal, pero existe otra, la llamada auto victimización que es aquella que se produce en los casos de víctima sin crimen.

\section{Victimología y justicia restaurativa}

El mencionar referente a la victimología, es citarla en la que, inicialmente la criminología solo atendía su actuar o estudio mediante la ciencia empírica e interdisciplinaria que se ocupa del estudio del crimen, de la persona del delincuente, la víctima y el control social del comportamiento delictivo.

Posterior a esta definición el estudio de la víctima tiene su origen en el positivismo criminológico (Gutiérrez et al., 2009), que inicialmente polarizó la explicación científica del comportamiento criminal alrededor del delincuente, ignorando en buena medida a la víctima, considerándola como un objeto neutro, pasivo, estático, que nada aporta a la génesis, dinámica y control del hecho criminal.

En la actualidad, se postula para las víctimas un tratamiento que les dé cabida en el ordenamiento procesal penal (Duce et al., 2014), pero sin contraponer los derechos de autor del delito a los de la víctima. Naturalmente hay que dar una respuesta a aquellas personas perjudicadas por el delito y habrá de ser el Sistema Penal el encargado de paliar, en la medida de lo posible, las consecuencias desfavorables que hayan marcado a una persona en cuanto víctima del delito.

El surgimiento de esta nueva victimología obedece a la justificación de una política de "ley y orden" y a la mayor rentabilidad de satisfacer a las víctimas que a los delincuentes, 
así como a la necesidad de establecer un contrapeso a la criminología crítica que, en su análisis, parecía eximir implícitamente al delincuente de la responsabilidad.

Ahora, en cuento al Derecho Penal; se ha orientado hoy en día, en forma unilateral hacia el autor del delito, dejando a la víctima en una posición marginal, cuando no limitada a su participación como testigo en el esclarecimiento del hecho delictivo; incluso como testigo se convierte en destinatario de serios compromisos y obligaciones, y portador de pocos o ningún derecho.

De esto, el actual redescubrimiento de la víctima y los estudios sobre el control social del crimen (Santacruz \& Santacruz, 2018), representan una positiva extensión del análisis científico hacia ámbitos desconocidos.

Ahora bien, dicha ampliación tiene como fin paliar este olvido de las víctimas por medio de estudios científicos que, desde las perspectivas interdisciplinarias, tengan por objeto a la víctima como tal, a sus características y su personalidad, tanto en relación con el hecho social (delito), como en función de su propia intervención en la dinámica social y criminal.

En el campo de la victimología se proponen como una cuestión íntimamente ligada a la aceptación e implementación del paradigma de la justicia restaurativa derivada desde su etiología por la Declaración de la Asamblea General de las Naciones Unidas sobre los Principios Básicos de Justicia para las Víctimas del Delito y del Abuso de Poder (1985).

\section{La mediación en el proceso penal mexicano.}

Por primera vez en la historia de nuestro país, la reforma constitucional de trascendencia del año 2008, fue impulsada por algunas buenas prácticas de varias entidades federativas, en otras palabras, esas entidades federativas comenzaron con la implementación del sistema acusatorio, y de la mediación (Silva \& Martínez, 2019) en materia penal, años antes a la reforma constitucional de 2008 .

Los acuerdos reparatorios no estaban legislados en el proceso, en la práctica se aplicaban los métodos alternativos (Silva, 2020) a aquellos delitos de querella y en los que permiten el perdón del ofendido, y en caso de tener éxito y las partes llegaran a un acuerdo, se aplicaran estas dos instituciones reguladas en el sistema procesal penal mixto vigente en aquel entonces.

El uso de los mecanismos alternativos no necesariamente va aparejado al sistema acusatorio; las entidades federativas que inician la implementación del sistema acusatorio previo al Código Nacional de Procedimientos Penales, e inclusive previo a la reforma de 2008, implementaron los mecanismos alternativos. Si bien es cierto que la reforma les dio fundamento y los códigos acusatorios impulsaron su utilización al ampliar el catálogo de los tipos de delitos aplicables, pero pensando únicamente en el efecto de sobreseimiento; es decir, no es un programa de Justicia Restaurativa, sino de terminaciones anticipadas o rápidas del proceso. También es cierto, que los Estados 
no lograron establecer un estándar de legislación, ni de buenas prácticas, respecto del uso de los mecanismos alternativos ni del sistema acusatorio, por lo que se tomó la decisión de estandarizar la regulación y aplicación de los mecanismos alternativos $\mathrm{y}$ del sistema acusatorio mediante un código y ley única.

El Código Nacional de Procedimientos Penales, regula los acuerdos reparatorios (Barona, 2019) y remite a la ley especializada en la materia, los acuerdos extinguen la pretensión punitiva del Estado, lo que nos confirma la idea de terminaciones rápidas, basadas en economía procesal y no en restaurar la paz social.

\section{DISCUSIÓN}

La victimología se desarrollará en un futuro como una auténtica disciplina de nivel científico, al mismo tiempo que como una práctica genuinamente humanista, acercarse al tema de la victimología, al acercarse a este tema, una de las generalizaciones simbólicas a las que se ha llegado es considerar que la victimología es una disciplina que se interesa por el estudio científico de la víctima. Por lo que la aplicación del dictamen víctima integral a ofendidos o derechohabientes; aporta una mayor amplitud en cuanto al rubro de la relación del daño que hoy en día solo está limitada a resarcimientos cuantitativos (cantidad económica). Su aplicación debe de realizarse a los que han sufrido los delitos de forma violenta, tales como: violación, violencia familiar, feminicidio, secuestro, homicidio, entre otros.

\section{REFERENCIAS}

1. Barona Vilar, Silvia. (2019). Mediación y acuerdos reparatorios en la metamorfósica justicia penal del siglo XXI. Boletín mexicano de derecho comparado, 52(155), 685-720. https://doi.org/10.22201/iij.24484873e.2019.155.14945

2. Cámara de Diputados. (2014). Código Nacional de Procedimientos Penales. México.

3. Cuarezma, Terám, Sergio. (s.f.). La victimología. Instituto Interamericano de Derechos Humanos.

4. Duce J, Mauricio, Moreno H, Leonardo, Ortiz de Urbina Gimeno, Íñigo, Maldonado F, Francisco, Carnevali R, Raúl, Matus A, Jean Pierre, Jiménez A, María Angélica, Neira, Marcela, Salinero E, Sebastián, \& Ramírez G, Cecilia. (2014). La víctima en el sistema de justicia penal: Una perspectiva jurídica y criminológica. Política criminal, 9(18), 739-815. https://dx.doi.org/10.4067/S0718-33992014000200014

5. Fattah, Ezzat. (2014). Victimología: pasado, presente y futuro. Revista electrónica de ciencia penal ycriminología,33(1), 17-46.

6. Gutiérrez de Piñeres Botero, Carolina, Coronel, Elisa, \& Andrés Pérez, Carlos. (2009). Revisión teórica del concepto de victimización secundaria. Liberabit, 15(1), 49-58.

7. Márquez Cárdenas, Alvaro E. (2011). LA VICTIMOLOGÍA COMO ESTUDIO. REDESCUBRIMIENTO DE LA VÍCTIMA PARA EL PROCESO PENAL. Prolegómenos. Derechos y Valores, XIV (27),27-42

8. Mejías Rodríguez, Carlos Alberto (2014). Retos y desafíos del derecho penal y la 
criminología en América Latina. IUS. Revista del Instituto de Ciencias Jurídicas de Puebla A.C., VIII (34),7-20.

9. Naciones Unidas. (1985). Declaración sobre los principios fundamentales de justicia para las víctimas de delitos y del abuso de poder.

10. Santacruz Fernández, Roberto, \& Santacruz Morales, David. (2018). El nuevo rol de la víctima en el sistema penal acusatorio en México. Revista de Derecho (Universidad Católica Dámaso A. Larrañaga, Facultad de Derecho), (17), 85-112. https:// dx.doi.org/10.22235/rd.v0i17.1572

11. Silva-Hernández, Francisca. (2020). Hacia una comprensión del conflicto en justicia alternativa. Revista de Investigaciones Universidad del Quindío, 32(1), 61-65. https://doi.org/10.33975/riuq.vol32n1.435

12. Silva Hernández, F., \& Martínez Prats, G. (2019). La justicia alternativa como derecho humano. JURÍDICAS CUC, 15(1), 263-284. https://doi.org/10.17981/ juridcuc.15.1.2019.10

13. Vega López, Ayeisa. (2017). La doble victimización de adolescentes en conflicto con la norma legal. Universidad de La Habana. 2017. Número 283. 126-136. 